\title{
An examination of kindergarten teachers' beliefs about creative pedagogy and their perceived implementation in
} teaching practices

Zhaocun Li East China Normal University

Li Li University of Exeter

\begin{abstract}
The purpose of the present study was to uncover kindergarten teachers' beliefs about creative pedagogy, their perceived implementation of creative pedagogy in teaching practices, and factors contributing to differences between teachers' beliefs and practice in China. A questionnaire was used to collect data from 698 in-service kindergarten teachers in Shanghai, China. Results showed that teachers overall held positive attitudes towards the importance of four dimensions of creative pedagogy (namely possibility thinking, interpersonal exchange, self-initiated pursuit and teacher-oriented pursuit). Teachers also reported favorably about all these four dimensions in their practice. However, there is divergence between teachers' beliefs and their reported practice. Teachers had neutral beliefs about teacher-oriented pursuit but implemented this more in their reported practice. They had strong beliefs about possibility thinking, interpersonal exchange and self-initiated pursuit but they focused less on these aspects in teaching. Teachers themselves, family, and teaching materials and environment may be the key contributing factors to the divergence of beliefs and practice. These findings have implications for kindergarten teacher professional development programs and the implementation of creativity reform in China.
\end{abstract}

Keywords:

Creativity; Creative pedagogy; Kindergarten teacher; Teachers' beliefs; Teaching practice

\section{Introduction}

As the sensitive period in the development of creativity (Gardner, 1993; OECD, 2012), early childhood has been the focus of growing attention in educational policy in recent years. Creativity has been included in curriculum frameworks in many countries, such as "creative development" (in Great Britain) (QCA/ DfEE, 2000; DCSF, 2008), "art, culture and creativity" (in Norway) (NMOER, 2012), "creative development" (in Georgia ,USA) (Georgia Department of Early Care and Learning, 2011), "creativity and culture"(in Iceland) (MOESC, 2012), "the development of creative and aesthetic appreciation" (in India) (MWCD, 2012), and "expression and creativity"(in China) (MOE, 2012). 
However, creative education cannot be promoted by issuing policy documents alone. Teachers play a critical role in interpreting and enacting policy documents (OECD, 2003), and their beliefs may support or undermine how learners experience these policy decisions (Fives \& Buehl, 2016). Thus, the implementation of creativity educational policies requires consideration of teachers' beliefs.

It is widely believed that teachers' beliefs guide and influence their practices. Nevertheless, inconsistency between their beliefs and teaching behaviors has also been reported (Buehl \& Beck, 2015; Leggett, 2017). Teachers may recognize creativity education but, faced with an ever-increasing academic load as well as standardized testing, creative pedagogy is often a lower priority (Mullet et al, 2016).

Therefore, in order to facilitate and foster creativity in early years' education, it is necessary to obtain an in-depth understanding of teachers' beliefs regarding creative pedagogy and their teaching practices. It may help teachers clarify the means to foster children's creativity more efficiently, provide policy-makers with insights into the improvement of policy implementation, and inform teacher educators about how to raise the quality of teaching in creative education. In this study, we aim to investigate kindergarten teachers' beliefs about creative pedagogy and their perceived implementation of it in their classroom, taking a Chinese context as an example.

\section{The Chinese context}

In China, kindergarten education for children of 3-6 years old is the main type of early childhood education, with the two categories of provision being state kindergarten and private kindergarten. Since 2010, the government has strengthened the public early childhood education system. According to program quality rating standards, these kindergartens are classified into three levels, from high to low: model kindergartens, first tier kindergartens and second tier kindergartens. Due to the shortage of kindergarten teachers, graduates majoring in early childhood education or other areas such as music, dancing, drawing and English, may become kindergarten teachers as long as they pass the teacher qualification test.

Since the beginning of the new century, the fostering of children's creativity has taken a leading role in education in China ( $\mathrm{Li}, 2010)$, with a greater emphasis on a more creative-driven early childhood curriculum (Zhu \& Zhang, 2008). In 2001, the Ministry of Education (MOE) launched a new curriculum reform in the basic education field, and published the Guidance for Kindergarten Education (trial version). This publication promotes the views of children as active and creative participants in the process of learning, and the pedagogy of exploration, negotiation, communication, collaboration and participation is strongly advocated. In 2012, the Guideline for Learning and Development of Children Aged $3 \sim 6$ was approved by the MOE. As an essential domain, "expression and creativity" was proposed to encourage children to express their feelings and imagination creatively in an art activity. The importance of the child-centered approach towards learning was further emphasized, which involves curiosity, interest, self-initiative, concentration, daring to inquire, enjoying imagination and being creative. 
It can be seen from these policies that early childhood education in China is undergoing a period of transformation from traditional direct teaching, which focused on the transmission of knowledge and skills, to child-centered teaching, which attaches greater importance to the development of children's creativity (Li \& Johnston, 2015). However, putting the policy into practice is not easy. Prior research has also revealed that, while Chinese teachers value the significance of creativity, they know less about what counts as creativity and how to teach or develop creativity in classroom activities (Chien \& Hui, 2010). In particular, the emphasis in Chinese kindergarten education has been on enunciation, diction, memorization and self-confidence in speaking and performing; children are taught to deliver long rehearsed speeches flawlessly and to belt out songs with many verses (Zhu and Zhang, 2008). Therefore, it seems fair to say that Chinese early childhood education is experiencing a paradigm shift which requires research evidence to see what teachers understand by creative pedagogy and how they utilize it in their teaching.

\section{Literature review}

\subsection{Creativity in early childhood}

Creativity involves the ability to produce outcomes that are both novel and appropriate (Sternberg \& Lubart, 1999; Robinson, 2001). The literature has pointed out that all young children have creative potential (Sharp, 2004; NACCCE, 1999).

From the perspective of outcome, Leggett (2017) argued that even though an outcome may not be considered useful to society at large, if it is still novel for the child or useful to children's communities, then it is a creative act. Children do not possess the same experiences and knowledge as adults. At the developmental stage, children can have novel ideas and produce creative products that are new to themselves or to their age group (Runco, 2003).

From the perspective of process, Malaguzzi (1998) explains that "creativity becomes more visible when adults try to be more attentive to the cognitive processes of children than to the results they achieve in various fields of doing and understanding" (p.77). In such a process, children exhibit their creativity by thinking or behaving imaginatively, looking for the possibilities that others have not noticed (NACCCE, 1999; Craft, 2003), or they experience something in a new or slightly different way (Samuelsson \& Carlsson, 2008).

From the perspective of type, the differentiation between big-C creativity and little-c creativity further confirms the ability of being creative in early childhood (Craft, 2003). Compared with big-C creativity, which happens in a particular field and leads to the paradigm-shift of a domain, little-c creativity is used by all individuals, including young children, in their everyday life. It is the capacity for route-finding across the range of life's contexts. For example, in a playgroup which provides opportunities for children to explore independently and freely, a child may exercise little-c creativity in making choices, in making something of friendships, and in exploring specific activities such as role-play or construction with toy bricks. Furthermore, the studies on 'possibility thinking' deepen our understanding about 
creativity in early years (e.g, Craft, 2003; 2007; Burnard, Craft \& Grainger, 2006). As the core of little-c creativity, possibility thinking was encapsulated as the posing of the question 'what if?' in different ways and contexts, together with perspective taking, or 'as if' thinking (Craft, et al., 2013). Possibility thinking is not just for adults, because meaning-making, connections, and the stepping beyond 'what is' to 'what could be' are just as relevant for the child (Craft, 1999).

\subsection{Creative pedagogy in early childhood education}

As a means of efficiently unlocking the creative potential of children, creative pedagogy has drawn considerable attention from researchers. As a logical starting point, the distinction between teaching creatively and teaching for creativity lays a conceptual foundation for creative pedagogy. A NACCCE report (1999) defined teaching creatively as "using imaginative approaches to make learning more interesting, exciting and effective" (p.89), while teaching for creativity is a kind of teaching form which is intended to develop creative thinking or behavior among children. These two practices are closely interconnected (Jeffrey \& Craft, 2004). Additionally, from the standpoint of children, creative learning was proposed as another element of creative pedagogy, which underpins children's spontaneous learning with active and creative engagement (Lin, 2014).

The specific pedagogical strategies that encourage young children's creativity in early childhood education have been examined in a number of studies. Craft (1999) and Hui et al (2015) proposed that a playful approach is conducive to promoting young children's creativity. Malaguzzi (1998) highlighted the role of the child's interaction with adults and peers, pointing out that "the most favorable situation for creativity seems to be interpersonal exchange, with negotiation of conflicts and comparison of ideas and actions being the decisive elements" (p.76). To identify teachers' pedagogical practices that foster the critical aspect of children's creativity -possibility thinking, Cremin, Burnard, and Craft (2006) found that standing back, profiling learner agency, and creating time and space were three essential pedagogic elements. Sharp (2004) also proposed possible strategies for developing young children's creativity, including asking open-ended questions, being tolerant of ambiguity, modelling creative thinking and behavior, encouraging experimentation and persistence, and praising children who provide unexpected answers. In a three-year study exploring potentials for creativity in the mathematics and science education of 3-8 years old in nine European countries, Cremin et al (2015) suggested the following strategies: play and exploration, motivation and affect, dialogue and collaboration, problem solving and agency, questioning and curiosity, reflection and reasoning, and teacher scaffolding and involvement.

\subsection{Early childhood teachers' beliefs about creative pedagogy and their classroom practice}

Teachers' beliefs about creative pedagogy are their judgments and convictions about the best way to facilitate children's creativity in the classroom. Research suggests that teachers' pedagogical beliefs are closely linked to their classroom 
practices (Fives \& Buehl, 2016). Some researchers have found consistencies between teachers' beliefs and their practices whilst others have found inconsistencies (Buehl \& Beck, 2015; Leggett, 2017).

Regarding creative pedagogy, a number of studies have disclosed the gap between teachers' beliefs and their teaching practices. In their review of the literature on teacher perception of creativity, Mullet et al (2016) found that there is a "creativity gap" between teachers' verbal support for creativity and actual classroom practice. Based on the relevant literature, they indicated that teachers would not give priority to creative pedagogy when under academic pressure. Faced with students' poor performance in creative thinking and presenting ideas, as well as insufficient teaching time, teachers also show a contradictory attitude toward creative pedagogy (Cheng, 2010). Using early childhood teachers in Hong Kong as her sample, Cheung (2012) noted that the teachers had adequate knowledge about good practice for developing children's creativity, but this knowledge was not clearly reflected in their classroom practices. Ng and Smith (2004) asserted that teachers in the Asian classrooms may experience more paradox when implementing creative pedagogy than those from Western contexts. Under the strong influence of Confucian heritage culture, teachers do not usually favor children's creative behaviors which may challenge teacher authority and disrupt the hierarchical relationship between the teachers and students.

On the whole, although teachers' beliefs about creative pedagogy and their implementation of it in classroom practice have been gradually revealed in a number of studies, as yet there has been little systematic exploration of this issue (Huang \& Lee, 2015; Tanggaard, 2011). In order to fill this research gap, this study examines early childhood teachers' beliefs about creative pedagogy and their implementation of it in the Chinese context. The research questions addressed in this study are:

Q1: What are kindergarten teachers' beliefs about creative pedagogy?

Q2: To what degree do kindergarten teachers perceive that creative pedagogy is implemented in their own classroom practices?

Q3: What is the relationship between teachers' beliefs about creative pedagogy and their perception of implementing creative pedagogy in their classroom? And what are the factors contributing to the relationship?

\section{4、Methodology}

\subsection{Participants}

A total of 698 in-service teachers took part in the study. All of them are from kindergartens in Shanghai city. The overwhelming majority of the participants were female (93.3\%). This ratio reflects approximately the gender structure of kindergarten teachers in this area. Referring to the theories of teacher development stages (Shuell, 1990; Fuller \& Bown, 1975) and the reality of the professional development of kindergarten teachers in the Chinese context, the amount of teaching experience of the participants is divided into three groups: 0-3 years (novice teacher), 4-10years (proficient teacher), and more than 10 years (expert teacher). Details of the sample are reported in Table 1. 
Table 1

Sample demographics

\begin{tabular}{|c|c|c|}
\hline Background & Number & Percentage \\
\hline \multicolumn{3}{|l|}{ Gender } \\
\hline Female & 651 & 93.3 \\
\hline Male & 47 & 6.7 \\
\hline \multicolumn{3}{|l|}{ Age group } \\
\hline Below 25 years & 126 & 18.1 \\
\hline $26-30$ years & 234 & 33.5 \\
\hline $31-40$ years & 248 & 35.5 \\
\hline $40-50$ years & 80 & 11.5 \\
\hline Above 50 years & 10 & 1.4 \\
\hline \multicolumn{3}{|l|}{ Teaching experience } \\
\hline $0-3$ years & 147 & 21.1 \\
\hline $4-10$ years & 324 & 46.4 \\
\hline Above 11 years & 227 & 32.5 \\
\hline \multicolumn{3}{|l|}{ Qualifications } \\
\hline Secondary vocational school & 60 & 8.6 \\
\hline education & 192 & 27.5 \\
\hline Three-year college education & 434 & 62.2 \\
\hline Bachelor's degree & 12 & 1.7 \\
\hline Master' s degree & & \\
\hline \multicolumn{3}{|l|}{ Major of the first degree } \\
\hline Preschool education & 467 & 66.9 \\
\hline Non-preschool education & 231 & 33.1 \\
\hline
\end{tabular}

\subsection{Instrument}

In order to address the research questions, we conducted a survey and employed a questionnaire to collect data. The questionnaire consisted of the following four parts:

Part one comprises items of personal information, including gender, age, teaching experience, the first degree, major of the first degree, type of kindergarten and tier of kindergarten.

Part two is a sub-questionnaire asking participants about their beliefs regarding creative pedagogy. It was developed by Cheung and Leung (2013) in Chinese, based on the sample they employed in Hong Kong。 It examines what creative pedagogy kindergarten teachers believe important for fostering children's creativity and includes four dimensions which are composed of 22 items: self-initiated pursuit (SP), 8 items, such as "encouraging hands-on experiences" and "valuing children's interests"; interpersonal exchange (IE), 6 items, such as "opportunities for discussion and cooperation" and "letting children evaluate their work"; possibility thinking (PT), 5 items, such as " open-ended questions" and "encouraging thinking differently"; and teacher-oriented pursuit (TP), 3 items, such as "direct teaching" and "repeating exercises". The four dimensions are closely connected with the literature of creative 
pedagogy. SP is related to encouraging children to learn by themselves (e.g., Cheung \& Leung, 2013), in which children may explore independently and exercise their little-c creativity (e.g., Craft, 2003), and express themselves creatively (e.g., Leggett, 2017). IE is highlighted as the most favorable pedagogy for creativity (e.g., Malaguzzi, 1998). Cremin et al (2015) recognized the essentially social and collaborative nature of creative pedagogy and that dialogic engagement is characteristic of classroom creativity. PT is related to encouraging children to think broadly and differently from others (e.g., Cheung \& Leung, 2013). It suggests teachers should ask open-ended questions, be tolerant of ambiguity, and praise children's unexpected answers (Sharp, 2004). TP represents a teacher-directed approach; although Chan (2007) argued that this hinders the development of children's creativity, it is found to be prevalent among teaching practices in the Chinese context (Cheung, 2012). Respondents rate each of the 22 items in terms of their importance for developing children's creativity, using a five-point Likert scale ranging from $1=$ not at all important to $5=v e r y$ important. The model fit indices of the original version are $C F I=0.96, \chi^{2}=957.222, d f=410$, $R M S E A=0.052$ (Cheung \& Leung, 2013). In our study, the internal consistency coefficient of it is $\alpha=0.931$.

Part three is a sub-questionnaire asking participants about the degree of implementation of creative pedagogy perceived by teachers in their own classroom; it was developed based on Cheung and Leung's sub-questionnaire mentioned above and includes four dimensions and 22 items which correspond with those in part two. A five-point Likert scale was employed ranging from $1=$ no implementation at all to $5=$ total implementation. The goodness of fit for the model was evaluated in MPLUS. The results were $C F I=0.97, \chi^{2}=1003.08, d f=203, R M S E A=0.089$, and the $\alpha=0.94$. These indices indicate that the model fit of this sub-questionnaire is not as good as that of part one but is acceptable (Qiu \& Lin, 2009).

Part four concerns those factors which are influential in the implementation of creative pedagogy. It includes two sub-sections: the first contains multiple choices consisting of 7 items; the second involves one open-ended question: "Do you think there are other factors which impact on the implementation of creative pedagogy? If yes, please list them."

It is important to provide justification here for using the four dimensions of creative pedagogy in the context of China. As described in the above section, early childhood education in China is experiencing a paradigm shift from traditional direct teaching, which is characterized by TP, to child-centered teaching, which aims at the development of children's autonomy, independence and creativity (Liu \& Feng, 2005). The child-centered teaching advocated in the reform places more emphasis on child-initiated play, interaction among children, and children's exploration and question-posing (Liu \& Feng, 2005). In particular, while PT as a concept is derived from the UK, the questionnaire items of this dimension, such as "Asking open-ended questions" and "Encouraging thinking differently", are ideas advocated in the reform. Therefore, these four dimensions (TP, SP, IE and PT) are highly relevant to the theme of educational reform in China. The questionnaire based on these four dimensions offers the opportunity to examine teachers' beliefs and practices during the process of 
reform. Furthermore, the questionnaire developed by Cheung \& Leung (2013) was used in the context of Hong Kong, which shares with Shanghai similarity in educational beliefs, teacher quality and educational policy direction in early childhood education.

\subsection{Procedure}

Before formally launching the survey, a pilot study was conducted with eight kindergarten teachers. The results showed that participants were able to understand the questions, and that the time required for completing the questionnaire was approximately 10 mins.

For data collection, the questionnaire was uploaded onto a Chinese online survey platform called "Sojump". Snowball sampling was used to recruit the informants. In total, 721 teachers participated in the online survey during a period of two weeks. Altogether 698 valid questionnaires were included in the data analysis.

We collected informed consent from all participants before they completed the questionnaire. The informed consent makes it clear that agreeing to contact others is not a requisite for participating in the research. The researcher did not offer a reward or a "bounty" for participation.

The online questionnaire data were exported to SPSS 20.0 and processed with both descriptive and inferential statistical analysis. Scores for each dimension were added up to perform inferential statistical analysis. For the open-ended question, content thematic analysis was employed to generate the main themes of the teachers' replies, and the frequencies for each theme were counted.

\section{Findings}

The findings were categorized into subsections summarizing teachers' beliefs, self-reported practices, the relationship between beliefs and practices, and the factors which contribute towards this relationship.

\subsection{Teachers' beliefs about the importance of creative pedagogy}

Overall, the findings suggest that teachers hold positive attitudes towards the importance of creative pedagogy. As illustrated in Figure 1, the means for each section of creative pedagogy is above the median. 


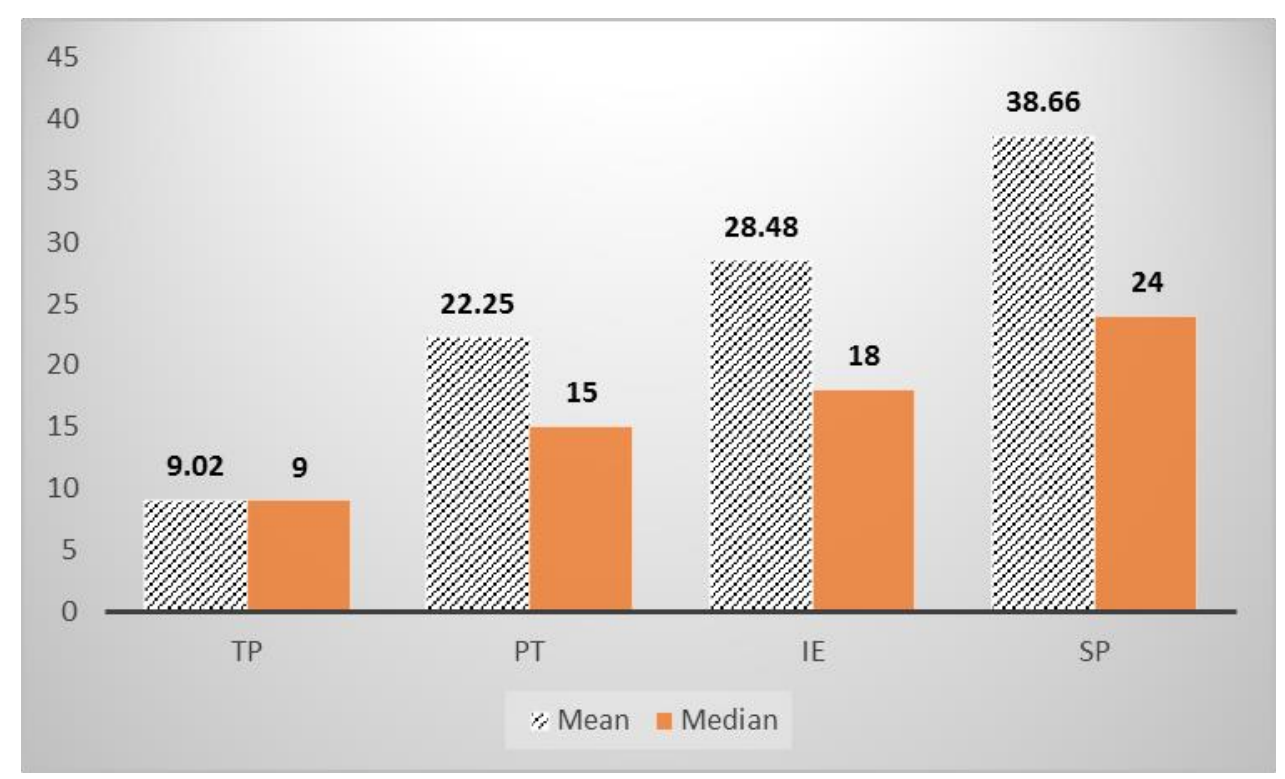

Fig.1. Teachers' perceptions of the importance of creative pedagogy $(\mathrm{N}=698)$

When the survey data were analysed in terms of contextual factors such as age, gender, kindergarten tier, teachers' first degree subject and so on, interesting results emerged. Specifically, ANOVA was carried out to determine whether there is a difference between teachers' beliefs about creative pedagogy and the above mentioned factors.

\section{Table 2}

Kindergarten level and teachers' beliefs about creative pedagogy（N=698）

\begin{tabular}{llllll}
\hline & Kindergarten & Mean & SD & $\boldsymbol{F}$ & $\boldsymbol{p}$ \\
& level & & & & \\
\hline Interpersonal exchange & Model & 27.8239 & 4.09621 & 4.255 & .015 \\
& First tier & 28.6570 & 3.00845 & & \\
& Second tier & 28.7087 & 2.89819 & & \\
Self-initiated pursuit & Model & 37.8553 & 5.32469 & 4.027 & .018 \\
& First tier & 38.7961 & 3.93872 & & \\
& Second tier & 39.0348 & 3.56335 & & \\
\hline
\end{tabular}

Analysis shows that significant differences exist between teachers' beliefs about creative pedagogy and kindergarten tier $(F=3.853, p=.022)$. More specifically, as indicated in Table 2, differences exist between kindergarten tier and teachers' beliefs about creative pedagogy in terms of interpersonal exchange and self-initiated pursuit ( $F=4.255, p=.015$ and $F=4.027, p=.018$ respectively).

Table 3

LSD results of IE and SP according to kindergarten level

\begin{tabular}{llll} 
Level I & Level J & Mean & $p$ \\
\hline
\end{tabular}




\begin{tabular}{lcccc}
\hline & & \multicolumn{3}{c}{ Difference } \\
\hline Interpersonal exchange & \multirow{2}{*}{ model } & First tier & $-.83306^{*}$ & .009 \\
& & Second tier & $-.88480^{*}$ & .009 \\
\multirow{2}{*}{ Self-initiated pursuit } & \multirow{2}{*}{ model } & First tier & $-.94077^{*}$ & .022 \\
& & Second tier & $-1.17944^{*}$ & .006 \\
\hline
\end{tabular}

Further analysis for Multiple Comparisons Post-hoc test was conducted by performing LSD (least significant difference). The results suggest that differences exist between teachers from model kindergartens, and teachers from first and second tier kindergartens with the latter two having higher means (see Table 3). In other words, teachers from both first and second tier kindergartens have stronger beliefs about the importance of creative pedagogy in aspects of interpersonal exchange and self-initiated pursuit.

\section{Table 4}

Differences between teachers who studied different subjects in IE and TP

\begin{tabular}{llrrrr}
\hline & Teachers' subject & \multicolumn{1}{c}{ Mean } & \multicolumn{1}{c}{$\boldsymbol{S D}$} & \multicolumn{1}{c}{$\boldsymbol{F}$} & \multicolumn{1}{c}{$\boldsymbol{p}$} \\
\hline \multirow{2}{*}{ Interpersonal exchange } & Early years education & 28.3105 & 3.55460 & 4.001 & \multirow{2}{*}{.046} \\
& Other subjects & 28.8355 & 2.57222 & & \\
Teacher-orient pursuit & Early years education & 8.8116 & 2.75362 & 6.887 & .009 \\
& Other subjects & 9.4286 & 3.23874 & & \\
\hline
\end{tabular}

As indicated in Table 4, ANOVA results suggest that there are significant differences between teachers' beliefs about creative pedagogy and their first degree subject in terms of interpersonal exchange and teacher-oriented pursuit $(F=4.001$, $p=.046 ; F=6.887, p=.009)$. Surprisingly, teachers who studied early year education in their first degree have lower means than those who studied other subjects.

A close examination of the $p$ value suggests that teachers who studied other subjects in their first degree have stronger beliefs about teacher-oriented pursuit, and the difference between the two groups of teachers in interpersonal exchange is relatively less significant $(p=.046)$. There seems to be a conflict between these two dimensions for teachers who studied other subjects in their degree: they have higher means in both areas.

\subsection{Teachers' reported practices}

Overall, the findings suggest that teachers believe that they adopt creative pedagogy in their teaching.

\section{Table 5}

Teachers' reported practice in creative pedagogy $(\mathrm{N}=698)$

\begin{tabular}{ccc}
\hline Median & Mean & $S D$ \\
\hline
\end{tabular}




\begin{tabular}{llll}
\hline Teacher-oriented pursuit & 9 & 10.8052 & 2.71705 \\
Possibility thinking & 15 & 21.2622 & 3.43311 \\
Interpersonal exchange & 18 & 25.9269 & 4.37537 \\
Self-initiated pursuit & 24 & 35.9312 & 5.41806 \\
\hline
\end{tabular}

As illustrated in Table 5, the means for each section of creative pedagogy practice is above the median, especially in the aspects of interpersonal exchange and self-initiated pursuit.

Again, ANOVA analysis was conducted to determine to what extent contextual factors contribute to teachers' practice. Results suggest that teaching experience, gender, age and kindergarten category contribute to differences in teachers' perceived practice of creative pedagogy in various dimensions. The differences with details are presented below.

\section{Table 6}

The relationship between teachers' practice in using creative pedagogy and teaching experience

\begin{tabular}{llllll}
\hline & $\begin{array}{l}\text { Teaching } \\
\text { experience } \\
\text { (years) }\end{array}$ & Mean & SD & $\boldsymbol{F}$ & $\boldsymbol{p}$ \\
\hline Self-initiated & $0-3$ & 34.7959 & 6.13762 & 4.376 & .013 \\
pursuit & $4-10$ & 36.0988 & 5.17341 & & \\
& Above 11 & 36.4273 & 5.17890 & & .018 \\
Possibility & $0-3$ & 20.5918 & 3.75035 & 4.017 & \\
Thinking & $4-10$ & 21.3272 & 3.29711 & & .001 \\
Interpersonal & Above 11 & 21.6035 & 3.36320 & & \\
exchange & $4-3$ & 24.7551 & 4.83224 & 7.231 & \\
& Above 11 & 26.0957 & 4.19348 & & \\
\hline
\end{tabular}

As shown in Table 6, a difference exists between teachers' practice of creative pedagogy and teaching experience, specifically in the aspects of self-initiated pursuit, possibility thinking and interpersonal exchange. In particular, there is a significant difference in the dimension of interpersonal exchange $(F=7.231, p=.001)$. Newly qualified teachers (i.e. those with teaching experience of 0-3 years) achieve lower means than the other groups in their perceptions of adopting creative pedagogy in practice.

Table 7

LSD results of IE, PT and SP according to teaching experience

\begin{tabular}{lllll}
\hline & $\begin{array}{l}\text { Teaching } \\
\text { experience I }\end{array}$ & $\begin{array}{l}\text { Teaching } \\
\text { experience J }\end{array}$ & Mean Difference & $p$ \\
\hline Interpersonal exchange & $0-3$ & $4-10$ & $-1.34058^{*}$ & .002
\end{tabular}




\begin{tabular}{lclll} 
& & Above 11 & $-1.68983 *$ & .000 \\
Possibilitythinking & $0-3$ & $4-10$ & $-.73532 *$ & .031 \\
& & Above 11 & $-1.01169 *$ & .005 \\
Self-initiated pursuit & $0-3$ & $4-10$ & $-1.30285^{*}$ & .015 \\
& & Above 11 & $-1.63139 *$ & .004 \\
\hline
\end{tabular}

Further analysis for Multiple Comparisons Post-hoc test by performing LSD suggests that the main differences in interpersonal exchange, possibility thinking and self-initiated pursuit are between newly qualified teachers and other teachers. As seen in Table 7, there exist significant differences between the teachers with less than three years and 4-10 years $(p=.002)$, and more than 11 years $(p=.000)$. However, there is no difference observed between teachers of 4-10 years and above 11 years of experience in terms of their practice.

Table 8

Gender differences in self-initiated pursuit

\begin{tabular}{llcccc}
\hline & Gender & Mean & SD & F & \multicolumn{1}{c}{$\boldsymbol{p}$} \\
\hline \multirow{3}{*}{ self-initiated pursuit } & Male & 34.0426 & 7.96175 & & \\
& Female & 36.0676 & 5.16870 & 6.496 & .006 \\
\hline
\end{tabular}

As shown in Table 8, gender also contributes to differences in teachers' practice in adopting creative pedagogy, especially in self-initiated pursuit, with female teachers having higher means ( 36.07 vs $34.04 ; F=6.496 ; p=.006$ ). This suggests that female teachers tend to implement creative pedagogy in the aspect of self-initiated pursuit. Interestingly, teachers do not believe gender has any influence at all on beliefs and practice (Also see section below: Figure 2).

\section{Table 9}

Kindergarten category differences in self-initiated pursuit

\begin{tabular}{llllll}
\hline & Category & Mean & SD & F & $\boldsymbol{p}$ \\
\hline Self-initiated pursuit & State-owned & 36.0334 & 5.30173 & 4.214 & .041 \\
& Private & 34.2051 & 6.96298 & &
\end{tabular}

Finally, as shown in Table 9, kindergarten category contributes to differences between teachers' practice in creative pedagogy in the aspect of self-initiated pursuit, with teachers in state kindergartens having a higher means ( 36.03 vs $34.21 ; F=4.214$; $p=0.041$ ).

\subsection{Relationship between teachers'beliefs and practice, and contributing factors}


Pearson correlation was performed to identify the relationship between teachers' beliefs about creative pedagogy and their reported practices, and the results suggest that this relationship is positive $(p=.000)$.

\section{Table 10}

Differences between teachers' beliefs and practice

\begin{tabular}{llccc}
\hline Dimension & $\begin{array}{l}\text { Mean } \\
\text { differences }\end{array}$ & SD & T & $p$ \\
\hline $\begin{array}{l}\text { Possible Thinking COG__Possible Thinking } \\
\text { ACT }\end{array}$ & 1.26074 & 3.22485 & 10.329 & .000 \\
$\begin{array}{l}\text { Interpersonal exchange COG_Interpersonal } \\
\text { exchange ACT }\end{array}$ & 2.55731 & 4.08907 & 16.523 & .000 \\
$\begin{array}{l}\text { Self-initiated pursuit COG__ Self-initiated } \\
\text { pursuit ACT }\end{array}$ & 2.72923 & 5.18327 & 13.911 & .000 \\
$\begin{array}{l}\text { Teacher-oriented pursuit } \\
\begin{array}{l}\text { Teacher-oriented pursuit ACT } \\
\hline\end{array}\end{array}$ & & & & \\
\hline
\end{tabular}

Paired-sample t-test was also performed to determine the differences between teachers' beliefs and practice in the four dimensions. The results in Table 10 suggest that there are very significant differences between teachers' beliefs and practice in all four dimensions $(p=.000)$. It is interesting to note that a negative relationship is identified between teachers' beliefs about teacher-oriented pursuit and their reported practice in this aspect $(T=-18.12)$. This suggests that teachers may have relatively weaker beliefs about teacher-oriented pursuit but adopt this practice more in teaching. On other three dimensions, teachers had positive beliefs, but they focus less on these aspects in teaching.

Given these significant differences between teachers' beliefs and reported practice, teachers were also asked to select all those factors which influence their practice. This was a multiple choice item and it elicited 2952 responses. 


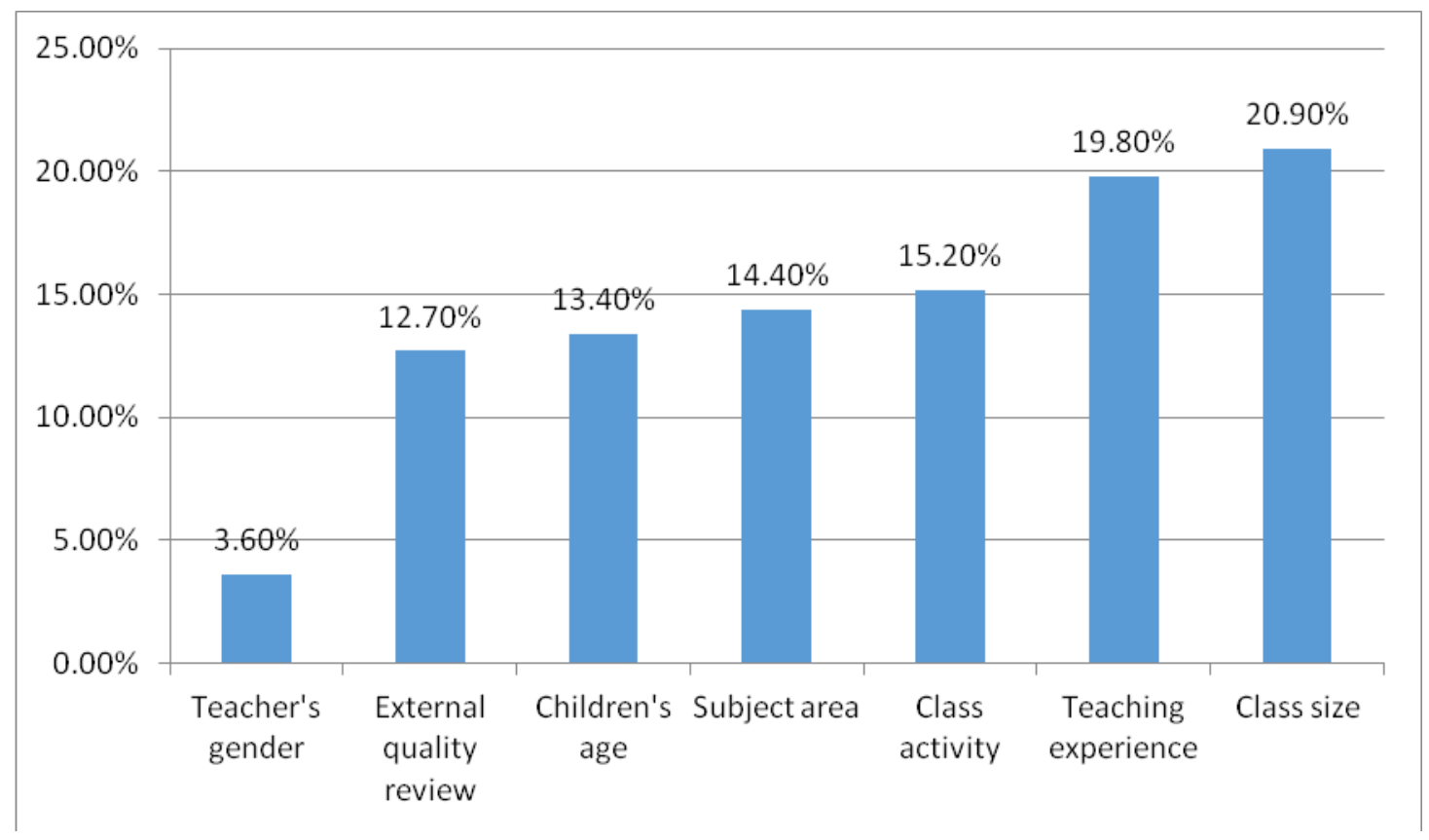

Fig. 2. Contributing factors towards differences between beliefs and practice

As shown in Figure 2, frequency analysis suggests that the most significant factors selected from the list of options are class size, with 616 responses accounting for $20.9 \%$; teaching experience, with $19.8 \%$ of the total responses $(n=584)$; class activity $(15.2 \% ; n=450)$; subject area and children's age with $14.40 \%$ and $13.40 \%$ of the total responses ( $n=426,397$ respectively); and finally teacher gender, accounting for only $3.6 \%$ of the total responses.

Table 11

Further contributing factors which teachers added

\begin{tabular}{|c|c|c|}
\hline Main theme & Frequency & Sub-theme and No. \\
\hline Teacher & 64 & $\begin{array}{l}\text { Pedagogical knowledge and skills }-25 \\
\text { Workload and pressure }-21 \\
\text { Educational beliefs }-12 \\
\text { Personality }-6\end{array}$ \\
\hline Family & 45 & $\begin{array}{l}\text { Cooperation and interaction between teachers and } \\
\text { parents }-14 \\
\text { Family education, beliefs and style- }-12\end{array}$ \\
\hline $\begin{array}{l}\text { Teaching material } \\
\text { and environment }\end{array}$ & 45 & $\begin{array}{l}\text { Teaching facilities and toys }-27 \\
\text { Space-14 }-14 \\
\text { Teacher/learner ratio-_ }-4\end{array}$ \\
\hline Learner & 39 & $\begin{array}{l}\text { Experience }-14 \\
\text { Cognitive level }-10 \\
\text { Individual differences }-14\end{array}$ \\
\hline Curricula and teaching & 25 & $\begin{array}{l}\text { Curriculum -- } 17 \\
\text { Teaching objective and approach ---8 }\end{array}$ \\
\hline
\end{tabular}




\begin{tabular}{lll}
\hline $\begin{array}{l}\text { Leadership and } \\
\text { management }\end{array}$ & 21 & $\begin{array}{l}\text { Kindergarten ethos }-4 \\
\text { Leadership }-13\end{array}$ \\
Society & 9 & Assessment and management -4
\end{tabular}

Apart from the options provided, teachers added a further 249 factors to the list (see Table 11). Teachers, family, and teaching material and environment were the factors most frequently mentioned by the teachers, with 64,45 and 45 responses respectively. Concerning the factor 'teachers', participants believe that teachers' knowledge of pedagogy and skills, teaching workload and pressure, educational beliefs and personality can influence teachers' beliefs and the implementation of creative pedagogy. Regarding 'family' aspects, the participants believe that cooperation and interaction between teachers and parents are important, as well as family education, beliefs and style. With regards to teaching material and environment, participants mentioned the provision of appropriate facilities and toys, space, and the teacher/learner ratio.

\section{Discussion and implications}

This study set out to investigate teachers' beliefs and reported practice of creative pedagogy in early childhood education: to find out what their beliefs and practice are, and to determine those factors which influence their understanding and practice of creative pedagogy. A number of key themes emerged from the findings and these areas of interest will be discussed according to the research questions.

\subsection{Teachers' beliefs about creative pedagogy}

The findings suggest that the surveyed teachers hold strong beliefs about three dimensions of creative pedagogy (namely possibility thinking, interpersonal exchange and self-initiated pursuit) but that they are neutral about teacher-oriented pursuit. These findings are consistent with Cheung \& Leung's (2013) study. The study further adds value in defining common characteristics of pre-school teachers' beliefs about creative pedagogy within Chinese society. Possibility thinking, interpersonal exchange and self-initiated pursuit have been identified as essential features of creative pedagogy in previous studies (e.g. Craft, 1999; Malaguzzi, 1998; Cremin, Glauert, Craft, Compton, and Stylianidou, 2015), and are further highly accepted by the pre-school teachers in the present study. However, while receiving relatively lower ratings, teacher-oriented pursuit, involving activities such as directed teaching, stressing correct answers, and repeating exercises, was also endorsed by participant teachers. A possible reason is the influence of traditional views on how to promote creativity in Chinese culture. A Chinese popular idiom, "practice makes perfection (Shu Neng Sheng Qiao 熟能生巧)" suggests the importance of repeating exercises and consistent hard work under the guidance of the teacher for learners to achieve excellence including high-level creativity (Niu \& Kaufman, 2013). Thus, the findings indicate the complexity and contradiction of teachers' belief systems during the 
transformation period from traditional direct teaching to child-centred teaching in China. In this period, new ideas and old ideas, even though they are conflicting, may exist side by side in the hearts of the teachers.

It is worth noting that kindergarten tier has an influence on teachers' beliefs. Model kindergartens are traditionally considered the best in educational quality ( $\mathrm{Li}$ and Zhang, 2016). However, the findings of this study seem to contradict this widely held assumption. Actually, compared with their colleagues from first and second tier kindergartens, model kindergarten teachers face more rigid evaluation criteria and onerous demonstrating tasks, which cost teachers a great deal of time and effort, and restrict them from fully implementing activities involving interpersonal exchange and self-initiated pursuit (Yu,2007; Deng, 2016). On the other hand, teachers from first and second tier kindergartens are less stressed by the expectations of outsiders to maintain the reputation of the kindergartens; thus, they have more flexibility and time to experience the role of interpersonal exchange and self-initiated pursuit in their practice. This finding suggests that keeping the balance of external assessment and intrinsic motivation is important. If too much obligation to apply creativity education is imposed on the teachers, they may experience less autonomy and intrinsic motivation for creativity education (Chien \& Hui, 2010; Ng \& Smith, 2004). This study suggests that the sociocultural context plays a significant role in how teachers understand and appropriate their pedagogical thinking. Clearly, in this case, the macro context has a more significant influence than the micro context in shaping teachers' pedagogical thinking. Thus, one strong implication from this research is that when any innovation is advocated by the local government, teachers and schools may need more support in changing their practices rather than just understanding the concept of the innovation. In this specific case, when creativity is highlighted and encouraged by the MOE, relevant policies regarding kindergarten evaluation and assessment may need to be adjusted.

This study further suggests that teacher's first degree subject influences their beliefs about creative pedagogy. Teachers who studied other subjects in their first degree did not receive systematic pre-service training on early childhood education. Since most of them do not object to the direct teaching approach, they are very receptive to new knowledge about early childhood education, including interpersonal exchange (Liu, 2008). On the other hand, teachers who graduate with a major in early childhood education have been taught at the pre-service stage that teacher-oriented pursuit is less useful in developing children's creativity. This contributes to shaping their negative beliefs about it. And, although they have also learned the importance of interpersonal exchange during their pre-service training, managerialism-oriented educational evaluation means that this pedagogy fails to achieve the expected effects. It seems that the teachers with a stronger professional reflective sense are often less optimistic about the role of this pedagogy in fostering children's creativity. Similar results were also found amongst Taiwanese teachers (e.g., Chien and Hui, 2010) and Greek teachers (e.g., Kampylis et al., 2009). This study suggests teachers have 
adequate knowledge about creativity education, but external constraints make them less confident about this creative pedagogy. Therefore, consistency between pre-service training and educational evaluation policies is critical for teachers' beliefs about creative pedagogy.

\subsection{Teachers' reported practice of creative pedagogy}

Firstly, this study suggests that newly qualified teachers are less likely to adopt self-initiated pursuit, possibility thinking and interpersonal exchange in practice from their own perspectives. This result is in line with that reported in the study by Chien and Hui (2010). According to Fuller and Bown (1975), newly qualified teachers are still in the survival stage of professional growth. Coping with discipline and guiding the class are ranked as major problems they have to face in their teaching practice (Raosas \& West, 2009; Maskit, 2013). It is therefore relatively difficult for them to emphasize interpersonal exchange, possibility thinking and self-initiated pursuit, which may result in a noisy classroom, especially in large classes containing more than 30 children in China. For theses teachers, deliberate practice may help their competence and confidence in creative pedagogy ( $\mathrm{Li}, 2016)$.

It is also worth noting that gender contributes to the differences in self-initiated pursuit: male teachers seem to be more rigid compared to female teachers. This result is parallel to the findings of Sumsion (2005). However, there are other previous studies which showed no significant difference in teachers' creativity fostering with reference to their gender (Forrester \& Hui, 2007; Ozkal, 2014; Dikici, 2014). Further study may be necessary to determine this issue.

Furthermore, teachers in private kindergartens are less inclined to focus on self-initiated pursuit than their colleagues in state kindergartens. We believe this is related to the level of teachers' professionalization. Most teachers in private kindergartens graduated from vocational schools; and the ownership ratio of teacher certification is very low (Wang, Hong and Pang, 2015). They are not familiar with the philosophy of leading children's independent exploration and learning through play (Fang \& Deng, 2014). Therefore, it is indispensable to develop training programs for these teachers focusing more on theoretical and practical knowledge and strategies for promoting creativity education (Chien and Hui, 2010).

A further point raised by this study is that there are divergences between teachers' beliefs and their reported practice. It seems that these dislocations are culture-bound and consistent inherently with the traditional teaching ethos of Confucian collectivistic culture ( $\mathrm{Ng} \&$ Smith, 2004). Although Confucianism is no longer advocated in current top-down educational reform in China, and no longer receives teachers' allegiance as highly as before, it still governs teachers' practical work in teaching. By contrast, possibility thinking, interpersonal exchange and self-initiated pursuit have their roots in Western individualistic culture and are 'ideals' for the majority of Chinese teachers (Craft, 2005). Although the ideas of such creative pedagogy are strongly advocated by China's education policies, and recognized by teachers, they are not easily compatible with local culture. Thus, teachers might find it 
difficult to sufficiently include creative pedagogy in their practice. On that aspect, Liu and Feng (2005) pointed out that the educational reform occurring in Chinese kindergartens is essentially a process of reconstruction of educational culture. The divergences of teachers' beliefs and practice in these four dimensions adds support to this view.

\subsection{Contributing factors to divergences of beliefs and practice}

This study has highlighted the key contextual factors that contribute to the divergences of teachers' beliefs and practice of creative pedagogy. The top three factors are the teachers themselves, family, and teaching materials and environment, which can be classified as internal and external factors. Figure 3 represents a conceptual map of these factors. In this figure, we can see that, as with any innovation or change in education, the teacher is a significant internal factor. This factor includes aspects such as the teachers' own knowledge and skills, the workload and work pressure they experience, their educational beliefs and experience, professional plans and personality. It is a complex system that involves teachers' past, present and future. In a nutshell, changes and adaptations are required on the teachers' part if creative pedagogy is to be implemented successfully in teaching.

The external factors are family, teaching materials and environment. The importance of parent involvement has been highlighted throughout the educational field (Fan \& Chen, 2001; Chien \& Hui, 2010). This study further stresses the importance of involvement and support from parents to help teachers make a link between classroom teaching and family learning in using creative pedagogy. Another external factor relates to teaching material and environment, which includes facilities and toys, space and the teacher/learner ratio. External factors require changes and support both at policy level and societal level. Promotion and recognition of creative pedagogy in developing $21^{\text {st }}$ century learners need to be clearly stated and advocated at these levels; in this way, individual teachers can be better supported when implementing such innovations.

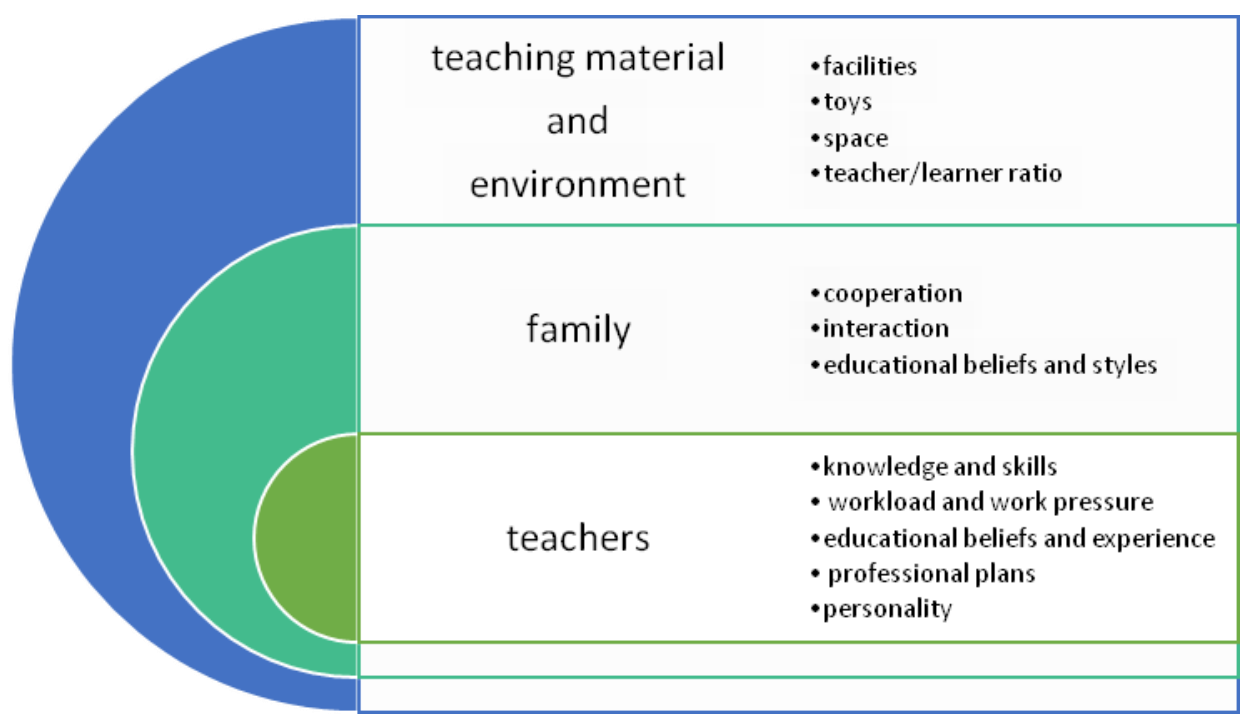

Fig. 3. A conceptual map of contextual factors contributing to differences between teachers' 
beliefs and practice.

\section{Limitations and future direction}

It is important to acknowledge the potential limitations in this study. This study was based on a self-reported questionnaire. Although some researchers have revealed that anonymous teachers' self-reports on their teaching are strongly correlated with classroom observations (Desimone, et al, 2010), a distinction must be acknowledged between what we say we do and what we do (Bretscher, 2014). The absence of direct interviews or observational data indicates the potential limitation of depending on self-reported data in that teachers may be reporting what they believe under ideal circumstances, or they may be responding to concepts used to structure the questionnaire with which they may not be familiar. Furthermore, the versions of creativity and creative pedagogy such as possibility thinking are drawn from predominantly Western sources. They may have different meanings across cultural contexts, which could be a possible reason for the divergence between teachers' beliefs and practice. Therefore, in order to obtain a more detailed and integrated picture of teachers' beliefs and their practices of creative pedagogy, there is a need for future research to employ a variety of research methods including class observation, in-depth interviews and cross-cultural comparison.

\section{Conclusion}

This study addresses several research questions related to kindergarten teachers' beliefs about creative pedagogy and their perceived implementation in teaching practices in China.

The results indicate that the participants hold positive attitudes towards the importance of creative pedagogy; and they assume that they adopt these pedagogies in their teaching. However, there is divergence between their beliefs and practice. They hold strong beliefs about possibility thinking, interpersonal exchange and self-initiated pursuit, but they continue to pay little attention to these aspects in their teaching. On the other hand, they hold neutral beliefs about teacher-oriented pursuit, but implement this more in their practice. These findings may reflect the complexity and contradiction of teachers' beliefs and practice. It is clear from the findings that various internal and external factors contribute to the divergences and these factors are closely interrelated. In particular, contextual factors play a key role. So by focusing on teachers' beliefs and practice by means of a survey, this study highlights an important issue for early childhood education in the process of implementing creative pedagogy; that is, there is a strong need to investigate teachers' understanding and beliefs about the pedagogy as they are not only the gatekeeper but also the executer of the innovation. The divergence is important here, and it remains to be seen how Chinese teachers and early year educators, as well as policy makers, can take a broader view of creative pedagogy in the existing educational system to facilitate its implementation. 
Furthermore, by analyzing contextual factors we reveal some interesting results which differ from the commonly-held hypotheses, and highlight the ecological and complex characteristic of the implementation of creative education. These results may inspire us to think further about creative pedagogy and teacher's professional development. Besides the personal factors of teachers, the factors of parent, teaching material and environment are also significant. Therefore, apart from strengthening teacher training, it is important for policy makers and educational administrators to improve parent engagement and home-kindergarten cooperation and to establish a creativity-friendly environment by, for example, reducing class size, providing abundant and appropriate teaching material and changing the evaluation system.

Additionally, from a cultural perspective, this paper reveals that the implementation of creative pedagogy is also culture-bound. It involves the interaction of Eastern collectivistic cultures and Western individualistic cultures. The challenge from cultures must be given sufficient attention when creative pedagogy is initiated by top-down reform mode in collectivistic cultures. As pointed out earlier, one option for stakeholders would be to transform educational realities at the same time that they appropriate them in practice and in reconstructing the concept of creative pedagogy, and it is this very activity that ensures the teachers' ability to cope with any pressure and problems that obstruct their way in their practical work. A broader understanding of creative pedagogy from the Chinese perspective and from the practitioners' perspective might assist in furthering the construction and reconstruction of the idea of creative pedagogy.

\section{Acknowledgments}

We would like to express our sincere appreciation to professor Rebecca Hun Ping Cheung, who kindly permitted us to use the Chinese version questionnaire on teachers' beliefs on creative pedagogy constructed by her. This study was sponsored by the Peak Discipline Construction Project of Education at East China Normal University, China.

\section{References}

Bretscher, N. (2014). Exploring the quantitative and qualitative gap between expectation and implementation: a survey of English mathematics teachers' uses of ICT. In A. Clark-Wilson, O. Robutti, \& N. Sinclair (Eds.),

The mathematics teacher in the digital era: an international perspective on technology focused professional development (pp. 43-70). Dordrecht: Springer.

Burnard, P., Craft, A., \& Grainger, T. (2006). Possibility thinking. International Journal of Early Years Education, 14(3), 243-262.

Buehl, M.M., \& Beck, J.S. (2015). The relationship between teachers' beliefs and teachers' practices. In H. Fives \& M.G. Gill (Eds.), International handbook of research on teachers' belief (pp. 66-84). New York: Routledge.

Chan, D. W. (2007). Creative teaching in Hong Kong schools: Constraining and challenges. Educational Research Journal, 22(1), 1-12. 
Cheng, V. M. Y. (2010). Tensions and dilemmas of teachers in creativity reform in a Chinese context. Thinking Skills and Creativity, 5(3), 120-137.

Cheung, R. H. P. (2012). Teaching for creativity: Examining the beliefs of early childhood teachers and their influence on teaching practices. Australasian Journal of Early Childhood, 37(3), 43-51.

Cheung, R. H. P., \& Leung, C. H. (2013). Preschool teachers' beliefs of creative pedagogy: important for fostering creativity. Creativity Research Journal, 25(4), 397-407.

Chien, C. Y., \& Hui, A.N.N. (2010). Creativity in early childhood education: Teachers' perceptions in three Chinese societies. Thinking Skills and Creativity, 5(2), 49-60.

Craft, A. (1999). Creative development in the early years: Some implications of policy for practice. The Curriculum Journal, 10(1), 136-150.

Craft, A. (2003). Creative thinking in the early years of education. Early Years, 23(2), 143-154.

Craft, A. (2007). Possibility thinking in the early years and primary classrooms. In A.G.Tan (Ed.), Creativity: A handbook for teachers (pp.231-250). Singapore: World Scientific.

Craft, A. (2005). Creativity in schools: Tensions and dilemmas. London: Routledge.

Craft, A., Cremin, T., Burnard, P., Dragovic, T., \& Chappell, K. (2012). Possibility thinking: Culminative studies of an evidence-based concept driving creativity? Education 3-13, 41(5), 538-556.

Cremin, T., Burnard, P., \& Craft, N. (2006). Pedagogy and possibility thinking in the early years. Thinking Skills and Creativity, 1(2), 108-119.

Cremin, T., Glauert, E., Craft, A., Compton, A., \& Stylianido, U. F. (2015). Creative little scientists: Exploring pedagogical synergies between inquiry-based and creative approaches in Early Years science. Education 3-13, 43(4), 404-419.

Deng, Z. L. Y. (2016). Practical deviation and rational return about the assessment of model kindergartens. Journal of the Chinese Society of Education, (5), 62-65. [in Chinese]

Department for Children, Schools and Families (2008). Statutory framework for the early years foundation stage. Nottingham: DCSF.

Desimone, L., Smith, T., \& Frisvold, D. (2010). Survey measures of classroom instruction: Comparing student and teacher reports. Educational Policy, 24 (2), 267-329.

Dikici, A. (2014). Relationships between thinking styles and behaviors fostering creativity: An exploratory study for the mediating role of certain demographic traits. Educational Sciences: Theory \& Practice, 14(1), 179-201.

Fan, X., \& Chen, M. (2001). Parental involvement and students' academic achievement: A meta-analysis. Educational Psychology Review, 13(1), 1-22.

Fang, J. H., \& Deng, H. P. (2014). The study on the developmental problem of private kindergartens. Journal of the Chinese Society of Education, (10), 45-49. [in Chinese]

Fives, H., \& Buehl, M. M (2016). Teachers' beliefs, in the context of policy reform. Policy Insights from the Behavioral and Brain Sciences, 3(1), 114-121.

Forrester, V., \& Hui, A. (2007). Creativity in the Hong Kong classroom: What is the contextual practice? Thinking Skills and Creativity, 2(1), 30-38.

Fuller, F., \& Bown, O. (1975). Becoming a teacher. In K. Ryan (Ed.), Teacher education. Chicago: University of Chicago Press.

Garder, H. (1993). Creating minds: An anatomy of creativity. New York, NY: Basic Books.

Georgia Department of Early Care and Learning. (2011). Georgia's pre-K program content standards. http://.ga.gov/documents/attachments/Content_Standards.pdf

Huang, X. H., \& Lee, J. C. K. (2015). Disclosing Hong Kong teacher beliefs regarding creative teaching: Five different perspectives. Thinking Skills and Creativity, 15, 37-47. 
Hui, A. N. N., Chow, B. W. Y., Chan, A. Y. T., Chui, B. H. T., \& Sam, C. T. (2015). Creativity in Hong Kong classrooms: transition from a seriously formal pedagogy to informally playful learning. Education 3-13, 43(4), 393-403.

Jeffrey, B., \& Craft, A. (2004). Teaching creatively and teaching for creativity: Distinctions and relationships. Educational Studies, 30(1), 77-87.

Kampylis, P., Berki, E., \& Saariluoma, P. (2009). In-service and prospective teachers' conceptions of creativity. International Journal of Thinking Skills \&Creativity, 4(1), 15 - 29.

Leggett, N. (2017). Early childhood creativity: Challenging educators in their role to intentionally develop creative thinking in children. Early Childhood Education Journal, 45 (6), 845-853.

Li, L. (2010). Introduction to Thinking Skills and Creativity: SE Asian Perspective. Thinking Skills and Creativity: SE Asian Perspective (special issue), 5 (3), 99-100.

Li, L. (2016). Integrating thinking skills in foreign language learning: what can we learn from teachers' perspectives? Thinking Skills and Creativity, 22, 273-288.

Li, X. M., Zhang, J. Z. (2016) On the Status of and Reflection on Chinese Model Kindergartens. Studies in Early Childhood Education, 257(5), 15-24.[in Chinese]

Li, Z., \& Johnston, A. (2015). Promoting creativity in Chinese classrooms: An examination based on educational policies. In Wegerif. R., Li, L., \&Kaufman, J. (Eds.). The Routledge international handbook of research on teaching thinking (pp. 168-180). London: Routledge.

Liu, Q. (2008). Research on the school-based training of non-preschool education major teachers. Studies in preschool education, 168(12), 22-25. [in Chinese]

Lin, Y. S. (2014). A third space for dialogues on creative pedagogy: Where hybridity becomes possible. Thinking Skills and Creativity, 13(3), 43-56.

Liu, Y., \& Feng, X. X. (2005). Kindergarten educational reform during the past two decades in mainland China: achievements and problems. International Journal of Early Years Education, 13(2), 93-99.

Maskit, D. (2013). First months in teaching-novices relate to their difficulties. Creative Education,4(4), 1-8.

Ministry of Education, Science and Culture. (2012). The Icelandic national curriculum guide for preschools. http://brunnur.stjr.is/mrn/utgafuskra/utgafa.nsf/xsp/.ibmmodres/domino/OpenAttachment/mrn/utgafuskra/utgafa. nsf/CA2C880C51C8CE0D00257A230058FCA5/Attachment/adskr_leiksk_ens_2012.pdf

Ministry Of Women and Child Development (2012). Early childhood education curriculum framework (draft). http://dietaizawl.weebly.com/uploads/2/3/5/9/23594870/ecce_curriculum_framework_draft.pdf

Mullet, D. R., Willerson, A., Lamb, K. N., Kettler, T. (2016).Examining teacher perceptions of creativity: A systematic review of the literature. Thinking Skills and Creativity, 21, 9-30.

Malaguzzi, L. (1998). History, ideas, and basic philosophy: an interview with LellaGandini. In: C. Edwards, L. Gandini, \& G. Forman (Eds), The hundred languages of children: The Reggio Emilia approach - advanced reflections (2nd ed.). Greenwich, CT: Ablex Publishing.

National Advisory Committee on Creative and Cultural Education. (1999). All our futures: Creativity, culture and education. London, England: Department for Education and Employment.

Ng, A. K., \& Smith, I. (2004). Why is there a paradox in promoting creativity in the Asian classroom? In S. Lau, A. Hui, \& G. Ng (Eds.), Creativity: When East meets West. Singapore: World Scientific.

Niu, W., \& Kaufman, J. C. (2013). Creativity of Chinese and American cultures: A synthetic analysis. The Journal of Creative Behavior, 47(1), 77-87.

Norwegian Ministry of Education and Research (2012). Framework plan for the content and tasks of kindergartens.

http://www.udir.no/Upload/barnehage/Rammeplan/Framework_Plan_for_the_Content_and_Tasks_of_Kinderga 
rtens_2011_rammeplan_engelsk.pdf

OECD (2003). Reviews of national policies for education: South Eastern Europe. OECD Publishing.

http://www.oecd.org/education/school/reviewsofnationalpoliciesforeducation.htm

OECD (2012). Starting strong III: A quality toolbox for early childhood education and care. OECD Publishing. http://dx.doi.org/10.1787/9789264123564-en

Ozkal, N. (2014). Relationships between teachers' creativity fostering behaviors and their self- efficacy beliefs. Education Research and Reviews, 9(18), 724-733.

Qiu, H. Z. \& Lin, B. F. (2009). Principles and applications of structural equation model. Beijing: China Light Industry Press.

Qualification and Curriculum Authority/ Department for Education and Employment (2000). Curriculum guidance for the foundation stage. London: Dfee/QCA.

Raosas, C., \& West, M. (2009). Teachers' beliefs about classroom management: Pre-service and inservice teachers' beliefs about classroom management. International Journal of Applied Educational Studies, 5, 55-61.

Robinson, K. (2001). Out of our minds: Learning to be creative. Oxford: Capstone.

Runco, M. A. (2003). Education for creative potential. Scandinavian Journal of Educational Research, 47(3), 317-324.

Sawyer, K. (2011). Structure and improvisation in creative teaching. New York: Cambridge university press.

Samuelsson, I. P. \& Carlsson, M. (2008). The Playing Learning Child: Towards a pedagogy of early childhood. Scandinavian Journal of Educational Research, 52(6), 623-641.

Shuell, T. J. (1990). Phases of meaningful learning. Review of Educational Research, 60(4), 531-547.

Sharp, K. (2004). Developing young children's creativity: what can we learn from research? Topic, 32, 5-12.

Sternberg, R. J., \& Lubart, T. L. (1999). The concept of creativity: Prospects and paradigms. In R. J. Stemberg

(Ed.), Handbook of creativity (pp. 3-15). Cambridge: Cambridge University Press.

Sumsion, J. (2005). Male teachers in early childhood education: issues and case study. Early Childhood Research Quarterly, 20(1), 109-123.

Tanggaard, L. (2011). Stories about creative teaching and productive learning. European Journal of Teacher Education, 34(2), 219-232.

Wang, M., Hong, X. M. and Pang, L, J. (2015). Focus on the development of non-government kindergarten teachers in China. Teacher Education Research, 27(3), 36-42. [in Chinese]

Yu, Y. P. (2007). The study on the development of model kindergartens. Early Education, (5), 4-7. [in Chinese]

Zhu, J. X., \& Zhang, J. (2008). Contemporary trends and developments in early childhood education in China. Early Years, 28(2), 173-182. 